\title{
A New Solution for the Transport of Fluids in Construction-Related Installations
}

\author{
N. Băran ${ }^{1}$, G.S. Fischer ${ }^{2} \&$ M.M. Stoican (Prisecaru) ${ }^{3}$ \\ ${ }^{1}$ Prof. Dr. Ing., ${ }^{2,3}$ Ph.D Student, ${ }^{1,2,3}$ Faculty of Mechanical Engineering and Mechatronics, Department of Thermodynamics, Engines, \\ Thermal and Refrigerating Equipment's, ${ }^{1,2,3}$ University Politehnica of Bucharest, Romania.
}

DOI: http://doi.org/10.38177/ajast.2021.5207

Copyright: (02021 N.Băran et al. This is an open access article distributed under the terms of the Creative Commons Attribution License, which permits unrestricted use, distribution, and reproduction in any medium, provided the original author and source are credited.

\section{ABSTRACT}

The paper presents the constructive solution and the operating principle for a rotating machine with two specially profiled rotors. It can function as a power machine (internal combustion engine, steam machine) or as a work machine (fan, compressor, volumetric pump).

When the machine operates as a pump, calculation relationships shall be established on the flow rate, drive power and actual efficiency.

The characteristics of the rotating volumetric pump shall be shown:

- Task characteristic: $\stackrel{\mathrm{g}}{V}=f\left(n_{r}\right)$;

- Power characteristic: $P=f\left(n_{r}\right)$;

- Yield characteristic: $\eta_{e}=f(\Delta p)$. Where, $\mathrm{n}_{\mathrm{r}}$ is the speed of the machine $[\mathrm{rot} / \mathrm{min}]$.

Keywords: Pump, Rotating Volumetric, Profiled rotors.

\section{Introduction}

From the working rotating machine class, a new type of rotating volumetric pump is presented in the paper which can carry any fluid substance [1], [2]:

- $\quad$ Pure (clean) liquids;

- Suspension liquids;

- Biphasic fluids (water+sand, water+ash);

- $\quad$ Fluid reologice.

The aspirated fluid is transmitted to discharge with minimal energy loss; thus, the engine moment is: $\stackrel{1}{M}=\stackrel{1}{F} \cdot \stackrel{1}{b}=F \cdot b \cdot \sin \alpha$ in which the arm (b) of the force $(\mathrm{F})$ is always perpendicular to the force, i.e. $\sin \alpha=\sin 90^{\circ}=1$. This leads to an advantage over piston machines and a biele-handle system.

In addition, the constructive solution does not contain elements that carry out alternative rectilinear movements; it has safe operation and easy maintenance.

Increased precision is required in its construction due to the fact that if there are high games between the rotor and the case, the volumetric efficiency of the pump will decrease.

The constructive solution proposed in this paper was designed and built in the laboratory of the Department of Thermotechnics, Engines, Thermal Equipment and Fridge son of the Faculty of Mechanical and Mechatronic Engineering, Polytechnic University of Bucharest, where a stand was made for her testing [3], [4]. This type of machine can be used in agriculture for irrigation of land areas, in constructions for supplying and pumping homes 


\section{AJAST}

Asian Journal of Applied Science and Technology (AJAST)

Volume 5, Issue 2, Pages 51-57, April-June 2021

with water at different elevations, in the energy industry at hydroelectric power plants, in the petrochemical industry for the circulation of high viscosity fluids, etc.

\section{The Constructive Solution and Function Principle}

The machine consists (figure 1) of two identical rotors $(2,5)$ of special shape that rotate at the same speed inside some housings $(1,4)$; The synchronous rotation of the rotors is ensured by two gear wheels fixed on shafts 7 and 9 .

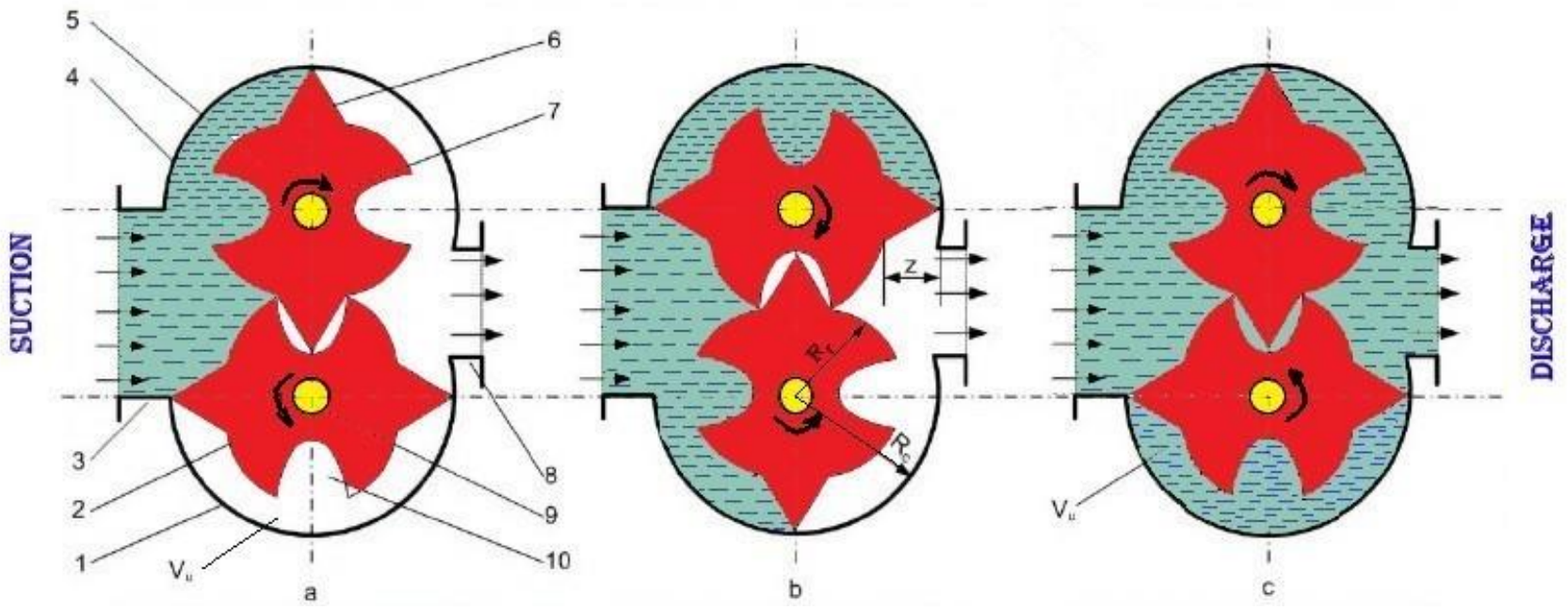

Fig.1. Position of Rotors after a Rotation of 90 Degrees

1 - lower housing; 2 - lower rotor; 3 - fluid suction chamber; 4 - upper housing; 5 - upper rotor; 6 - rotating piston of the upper rotor; 7 - driven shaft; 8 - fluid discharge chamber; 9 - driving shaft; 10 - cavity in which the piston of the upper rotor enters

Fluid that penetrates the suction chamber (3) is transported to the discharge chamber (8) by the rotating pistons (6). Figure $1(a, b, c)$ shows the flow of fluid after a 90 degrees rotation of both rotors. The fluid in the useful volume $\left(\mathrm{V}_{\mathrm{u}}\right)$, is between the two rotating pistons and the lower housing.

\subsection{Establishing the Calculation Relation of the Flow Rate Driven by the Machine}

At a complete rotation of the shafts $(7,9)$ will be transported from the suction to the discharge, two such volumetrics $\left(\mathrm{V}_{\mathrm{u}}\right)$.

$$
\stackrel{\mathrm{g}}{V}_{u}=2\left(\frac{\pi R_{c}^{2}}{2}-\frac{\pi R r^{2}}{2}\right) \cdot l \quad\left[m^{3} / r o t\right]
$$

The housing radius $\left(\mathrm{R}_{\mathrm{c}}\right)$ is the sum of the rotor radius $\left(\mathrm{R}_{\mathrm{r}}\right)$ and the piston height $(\mathrm{z})$ (figure 1$)$.

$$
R_{c}=R_{r}+z \quad[m]
$$

From equation (1) and equation (2) results:

$$
\stackrel{\mathrm{g}}{V}_{u}=\pi \cdot l \cdot \mathrm{z}\left(\mathrm{z}+2 \mathrm{R}_{\mathrm{r}}\right) \quad\left[m^{3} / r o t\right]
$$


The volumetric flow rate of fluid flowed by a single rotor of length $1[\mathrm{~m}]$ and speed $\mathrm{n}_{\mathrm{r}}$ [rot / $\left.\mathrm{min}\right]$ will be:

$$
\stackrel{\mathrm{g}}{V}_{u}=\pi \cdot l \cdot z\left(z+2 R_{r}\right) \cdot \frac{n_{r}}{60} \quad\left[m^{3} / s\right]
$$

The rotating machine has two identical rotors, so the flow rate transported by the machine will be:

$$
\stackrel{\stackrel{\mathrm{g}}{V}}{\mathrm{~m}}_{m}=2 \stackrel{\stackrel{\mathrm{g}}{V}}{u}_{u}=\pi l z\left(z+2 R_{r}\right) \cdot \frac{n_{r}}{30} \quad\left[\mathrm{~m}^{3} / s\right]
$$

It is observed that the volumetric flow rate increases linearly with the length (l), the radius of the rotor $\left(\mathrm{R}_{\mathrm{r}}\right)$ and with the speed $\left(\mathrm{n}_{\mathrm{r}}\right)$.

\subsection{Establishing the Calculation Relation of the Driving Power of the Machine}

The theoretical driving power of the machine is obtained with the relationship [5], [6]:

$$
P=\stackrel{\mathrm{g}}{V_{m}} \cdot \Delta p=\pi \cdot l \cdot z \cdot\left(z+2 R_{r}\right) \cdot \frac{n_{r}}{30} \cdot \Delta p[W]
$$

From the relationship (6) it is observed that the drive power is influenced by the flow rate (i.e. by the geometric parameters: 1 - the length of the rotor $[m] ; \mathrm{R}_{\mathrm{r}}-$ rotor radius $[m] ; \mathrm{z}$ - piston height $[m]$; and functional parameters: $\mathrm{n}_{\mathrm{r}}$ - machine speed $[\mathrm{rot} / \mathrm{min}] ; \Delta \mathrm{h}$ - hydrostatic load + pressure losses on the circuit; $\left[N / \mathrm{m}^{2}\right] ; p$ - the density of the circulated fluid $\left.\left[\mathrm{kg} / \mathrm{m}^{3}\right]\right)$ by the increase in pressure $(\Delta \mathrm{p})$ carried out by the pump between suction and discharge, of the nature of the circulated fluid. The increase in pressure achieved by the pump can also be expressed according to the geodesic pumping height $\left(\mathrm{H}_{\mathrm{g}}\right)$ of the water and the pressure losses occurring on both the suction circuit and the pump discharge circuit.

\section{Presentation of the Characteristic Curbes of the Rotating Volumetric Pump}

Relationships that determine the performance of a machine at different operating regimes, different from that of calculation (nominal) are called the characteristics of that machine.

Relationships can be analytical, graphical and are determined theoretically or experimentally.

The following characteristics have been determined from theoretical and experimental research:

- Task feature: $\stackrel{\mathrm{g}}{V}=f\left(n_{r}\right)$;

- Power feature: $P=f\left(n_{r}\right)$;

- Yield feature: $\eta_{e}=f\left(n_{r}\right)$.

Where: $\mathrm{n}_{\mathrm{r}}=100 \ldots 500[\mathrm{rot} / \mathrm{min}]$.

a) Task characteristic: $\stackrel{\mathrm{g}}{V}=f\left(n_{r}\right)$

In the flow rate calculation relationship, the values of the sizes of the built model are replaced: 


\section{AJAST}

$l=0,05[\mathrm{~m}] ; z=0,03[\mathrm{~m}] ; n_{r}=100,200,300,400,500[\mathrm{rot} / \mathrm{min}]$ and get the values from the table no. 1.

Table 1. Values of $\stackrel{\mathrm{g}}{V}=f\left(n_{r}\right)$

\begin{tabular}{|c|c|c|c|c|c|}
\hline $\mathrm{n}_{\mathrm{r}}[\mathrm{rot} / \mathrm{min}]$ & 100 & 200 & 300 & 400 & 500 \\
\hline$\stackrel{\mathrm{g}}{V}\left[\mathrm{~m}^{3} / s\right]$ & 0,00204 & 0,00408 & 0,00612 & 0,00816 & 0,0102 \\
\hline
\end{tabular}

Based on the data in table 1 , the function graph $\stackrel{\mathrm{g}}{V}=f\left(n_{r}\right)$ in figure 2 was plotted.

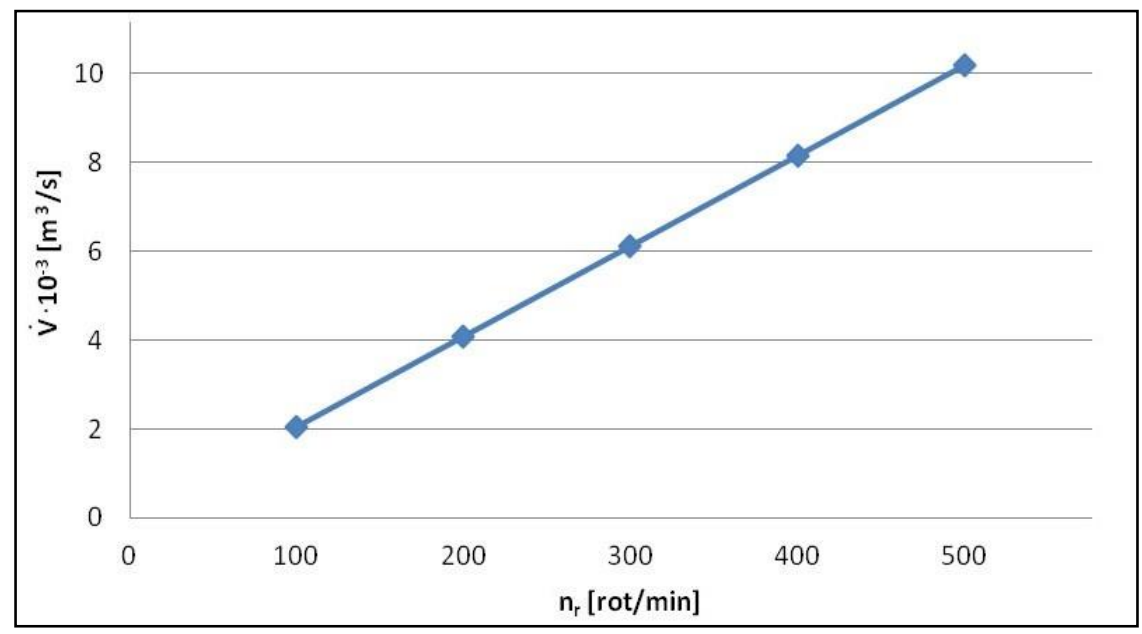

Fig.2. Graphical Representation of the function $\stackrel{\mathrm{g}}{V}=f\left(n_{r}\right)$

Figure 2 one can observe that the function has a linear variation, increasing with the increase in the speed of the work machine.

In the case of this operating equation sizes $1, \mathrm{z}, \mathrm{R}_{\mathrm{r}}[\mathrm{m}], \mathrm{n}_{\mathrm{r}}[\mathrm{rot} / \mathrm{min}]$ are input sizes (data) and $\stackrel{\mathrm{g}}{V}\left[\mathrm{~m}^{3} / s\right]$ is the output size of the rotating machine. Change in speed $\left(\mathrm{n}_{\mathrm{r}}\right)$ leads to change volumetric flow rate $(\stackrel{\mathrm{g}}{V})$.

b) Power characteristic: $P=f\left(n_{r}\right)$.

Taking into account that in relation (6), the increase in pressure $(\Delta \mathrm{p})$ can be written as follows [6]:

$$
\Delta p=\rho_{\mathrm{H}_{2} \mathrm{O}} \cdot g \cdot H
$$

Where, $\mathrm{H}$ represents the hydrostatic load, a residential building with a height of $\mathrm{H}=55\left[\mathrm{mH}_{2} \mathrm{O}\right]=5,5 \cdot 10^{5}\left[\mathrm{~N} / \mathrm{m}^{2}\right]$ was chosen.

Replacing $l=0,05[\mathrm{~m}] ; z=0,0,3[\mathrm{~m}] ; R_{r}=0,05[\mathrm{~m}]$ and $n_{r}=100 \div 500[\mathrm{rot} / \mathrm{min}]$, from the relationship (8)

$$
P=\stackrel{\mathrm{g}}{V_{m}} \cdot \Delta p=\pi \cdot l \cdot z \cdot\left(z+2 R_{r}\right) \cdot \frac{n_{r}}{30} \cdot \rho_{\mathrm{H}_{2} \mathrm{O}} \cdot g \cdot H \quad[W]
$$

the data in table 2 is obtained. 
Table 2. Values of $P=f\left(n_{r}\right)$

\begin{tabular}{|c|c|c|c|c|c|}
\hline $\mathrm{n}_{\mathrm{r}}[\mathrm{rot} / \mathrm{min}]$ & 100 & 200 & 300 & 400 & 500 \\
\hline$P \cdot 10^{3}[\mathrm{~W}]$ & 1,10 & 2,20 & 3,30 & 4,40 & 5,50 \\
\hline
\end{tabular}

Based on the data in table 2, the function $P=f\left(n_{r}\right)$ are plotted.

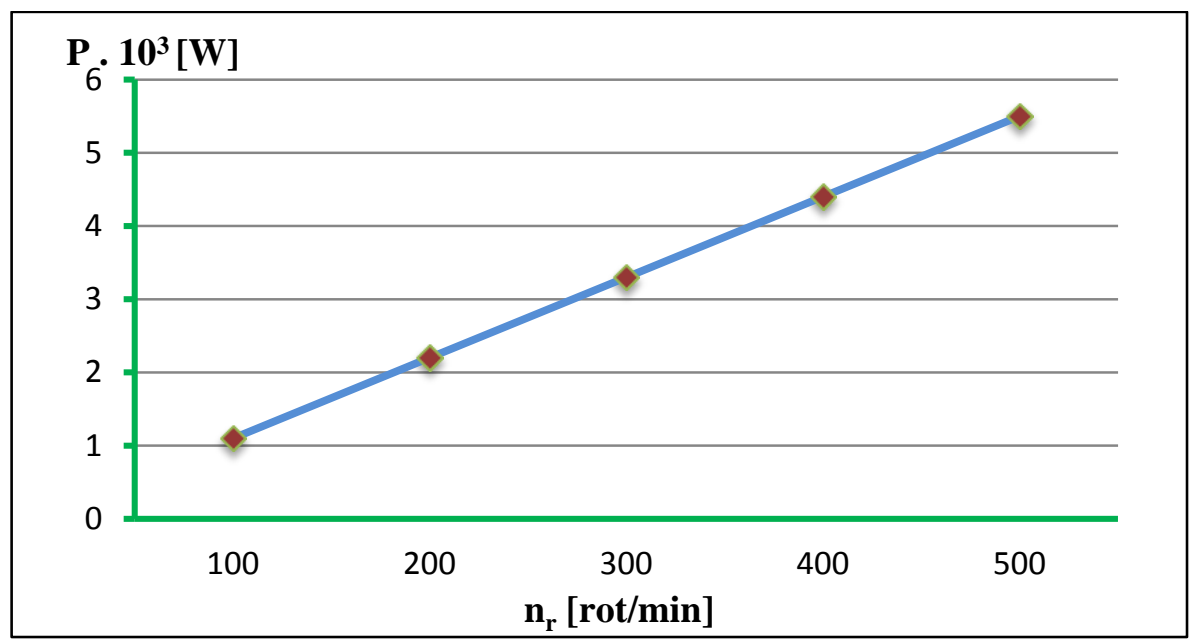

Fig.3. Graphical Representation of the function $P=f\left(n_{r}\right)$

c) Yield characteristic $\eta_{e}=f\left(n_{r}\right)$

This function reveals that when the fluid flow rate increases, the losses will increase. Thus the total efficiency of the machine is calculated with the relationship:

$$
\eta_{p}=\eta_{m} \cdot \eta_{v} \cdot \eta_{h}=\eta_{i} \cdot \eta_{m}
$$

The values $\eta$ for rotating pumps are $0,5 \ldots . .0,8$ [7], [8].

For the yield characteristic, account shall be taken of the fact that $\eta_{e}=\eta_{v} \cdot \eta_{m}$ the value 0,9 is adopted for $\eta_{m}$; the data in table 3 are obtained where $\stackrel{\mathrm{g}}{V}$ - the theoretical volumetric flow rate and $\stackrel{\mathrm{g}}{V_{r}}$ - the actual volumetric flow rate are adopted.

Table 3. Actual Yield Values based on Increase in Pressure

\begin{tabular}{|c|c|c|c|c|c|}
\hline$n_{r} \quad[\mathrm{rot} / \mathrm{min}]$ & 220 & 220 & 220 & 220 & 220 \\
\hline$\stackrel{\mathrm{g}}{V_{t}\left[d \mathrm{~m}^{3} / \mathrm{min}\right]}$ & 269,41 & 269,41 & 269,41 & 269,41 & 269,41 \\
\hline$\stackrel{\mathrm{g}}{V_{r}\left[d \mathrm{~m}^{3} / \mathrm{min}\right]}$ & 247 & 245 & 236 & 231 & 225 \\
\hline$\Delta p[\mathrm{bar}]$ & 0,20 & 0,21 & 0,22 & 0,23 & 0,24 \\
\hline
\end{tabular}


Volume 5, Issue 2, Pages 51-57, April-June 2021

\begin{tabular}{|c|c|c|c|c|c|}
\hline$\eta_{v}$ & 0,91 & 0,90 & 0,87 & 0,85 & 0,83 \\
\hline$\eta_{m}$ & 0,9 & 0,9 & 0,9 & 0,9 & 0,9 \\
\hline$\eta_{e}$ & 0,819 & 0,810 & 0,783 & 0,765 & 0,747 \\
\hline
\end{tabular}

Based on the data in table 3, the efficiency characteristic of the rotating machine was graphically represented (figure 4).

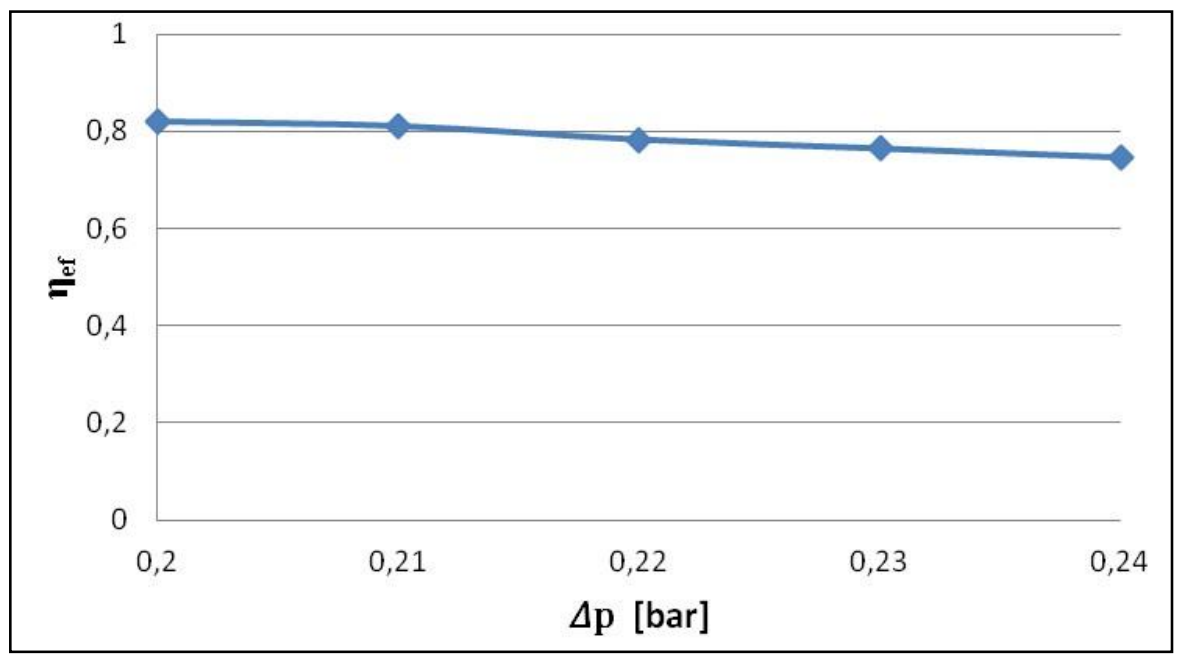

Fig.4. Graphical Representation of the

$$
\text { function } \eta_{e f}=f(\Delta p)
$$

Figure 4 shows that when it increases, it decreases because it decreases (increases volumetric losses). $\Delta p \eta_{e} \eta_{v}$ This confirms that when the speed increases, i.e. the car's, $\omega$ the efficiency of the machine will increase to a certain value, then it starts to decrease. From the experimental research carried out [9] it emerged that the pump has an effective yield of 0.77 value which is higher than at piston pumps [10].

\section{Conclusions}

(1) The constructive solution presented can carry clean fluids, multiphase fluids, as well as rheological fluids.

(2) The drive power of the machine is influenced by the nature of the fluid carry by the density of the fluid and by the value of the pumping height $(\Delta H)$.

(3) The actual efficiency of the rotating machine, following experimental research eating about $80 \%$, a good value for the current state of the research of this type of rotating machine. The rotating machine shown is not built on an industrial scale, thus being open for new collaborations.

\section{Declarations}

\section{Source of Funding}

This research did not receive any specific grant from funding agencies in the public, commercial, or not-for-profit sectors. 


\section{Competing Interests Statement}

The authors declare no competing financial, professional and personal interests.

\section{Consent to participate}

Not Applicable

\section{Consent for publication}

We declare that we consented for the publication of this research work.

\section{Availability of data and material}

Authors are willing to share data and material according to the relevant needs.

\section{Author's contribution}

All authors participated in overseeing laboratory work, data analysis, and manuscript writing and review

\section{References}

[1] N. Băran, I. Căluşaru, A. Detzortzis, "Research regarding the testing of a new type of rotating machine with profiled rotors", Journal of Materials Science and Engineering A 2 (3) 372-376, 2012, pp. 372-376.

[2] Motorga, "Influența parametrilor constructivi și funcționali asupra performanțelor mașinilor rotative cu rotoare profilate", Teză de doctorat, Universitatea Politehnica din București, 2011.

[3] N. Băran, P. Răducanu, et. al., "Bases of technical thermodynamics", Politehnica Press Publishing House, Bucharest, 2010.

[4] N. Băran, Maşini termice rotative de lucru, - Maşini cu rotoare profilate, Maşini cu palete, Editura Matrix ROM, Bucureşti 2001.

[5] Al. Dobrovicescu, N. Băran şi col., Elemente de termodinamică, Editura Politehnica Press, Bucureşti, 2009.

[6] C. Isbăşoiu, Tratat de mecanica fluidelor, Editura AGIR, București, 2011.

[7] Mihaela Constantin, Almaslamani Ammar Fadhil Shnawa, "Computing elements for the architecture of a new type of rotating volumetrictric pump", International Journal of Innovative Science, Engineering \& Technology, Vol. 5 Issue 5, pp. 112-115, 2018.

[8] N. Băran, D. Besnea, A. Motorga, "Elements of computing the architecture and manufacturing technology for a new type of profiled rotor", Proceedings International Conference, $6^{\text {th }}$ Workshop on European Scientific and Industrial Collaboration on promoting Advanced Technologies in Manufacturing, WESIC'08 Bucharest 25-26 September 2008, p.233-241.

[9] M. Hawas, "Research regarding the establishment of efficiency for a new type of rotating volumetrictric pump", International Research Journal of Engineering and Technology, Vol. 02. Issue 02, 2015, pp.796-800.

[10] M. Exarhu, "Pneumatic and hydraulic machine and installations", (in Romanian), SC. ANDOR SRL, Bucharest, 2011. 